\title{
Effects of Number of Atoms, Shell Thickness, and Temperature on the Structure of Fe Nanoparticles Amorphous by Molecular Dynamics Method
}

\author{
Dung Nguyen Trong ${ }^{1,2}$ and Van Cao Long ${ }^{1}{ }^{1}$ \\ ${ }^{1}$ Institute of Physics, University of Zielona Góra, Prof. Szafrana 4a, 65-516, Zielona Góra, Poland \\ ${ }^{2}$ Faculty of Physics, Hanoi National University of Education, 136 Xuan Thuy, Cau Giay, Ha Noi, Vietnam \\ Correspondence should be addressed to Dung Nguyen Trong; dungntsphn@gmail.com
}

Received 31 March 2021; Revised 3 August 2021; Accepted 16 August 2021; Published 2 September 2021

Academic Editor: Shangtong Yang

Copyright (C) 2021 Dung Nguyen Trong and Van Cao Long. This is an open access article distributed under the Creative Commons Attribution License, which permits unrestricted use, distribution, and reproduction in any medium, provided the original work is properly cited.

\begin{abstract}
This study aims to study the effect of several structural factors, such as number of atoms $(N)$, shell thickness $(d)$, and temperature $(T)$, on the structure of amorphous iron nanoparticle (amorphous nano-Fe) by using the molecular dynamics (MD) method with Sutton-Chen (SC) dip interaction and free boundary conditions. The structural parameters of amorphous nano-Fe include their size $(D)$, energy $(E)$, radial distribution function $(\mathrm{RDF})$, coordination number $(\mathrm{CN})$, and coordination number density $\left(\mathrm{CN}_{d}\right)$. The results show that the glass temperature $\left(T_{g}\right)$ and the first peak position $(r)$ of radial distribution function (RDF) have the values of $T_{g}=900 \mathrm{~K}$ and $r=2.55 \AA$, respectively. Furthermore, the values of parameters $D$ and $E$ are always proportional to $N^{-1 / 3}$ and $N^{-1}$, respectively. Regarding the effect of number of atoms, shell thickness, and the temperature on the structure of amorphous nano$\mathrm{Fe}$, we found that the increase in atoms number leads to decrease in the RDF height and increase in the coordination number $(\mathrm{CN})$. However, increasing temperature leads to decreasing the shell thickness of amorphous nano-Fe.
\end{abstract}

\section{Introduction}

As ferromagnetic material, iron nanoparticles (nano-Fe) exhibit a transition temperature $\left(T_{m}\right)$ in range from $T_{m}=1043 \mathrm{~K}$ to $T_{m}=1881 \mathrm{~K}[1]$. It was reported that reducing the size $(D)$ below $D=20 \mathrm{~nm}$, nano-Fe moved from ferromagnetic state to super-para-magnetic state without any residual magnetism. This phenomenon provides a various promising application of nano-Fe [2], including the design of high-speed storage [3], magnetic resonance cameras [4], catalysts [5], nonlinear optics [6], sensors [7], and biomedicine (separation of biological molecules $[8,9]$, drug transmission, target drug transport, marking of cells, and so on [10]). As reported, turning the size of nano-Fe might enhance their heat capacity, magnetism, and biomedical compatibility [11]. In this regard, various many methods have been used to study the effect of influencing factors, such as number of atoms, shell thickness, and temperature, on the structure and phase transition of iron nanoparticle, such as theory methods, experiment methods, and simulation $[12,13]$ methods such as Green function method [14, 15] and Monte Carlo (MC) method [16] and Bethe model [17]. Among these methods, the molecular dynamics simulation (MD) method has been considered a powerful tool in both theoretical and experimental studies. Based on the MD method for Fe bulk, several authors found that its first peak position $(r)$ of radial distribution function (RDF) was $r=2.55 \AA$ [18-20] whereas it was $r=2.54$, 2.618 , and $2.570 \AA$, by using the experiment method, Neutrons, and X-rays, respectively [21, 22]. Similarly, its coordinate number $(\mathrm{CN})$ was $\mathrm{CN}=13.23,12.92$, and 12.10 by using MD, Neutrons, and X-rays methods, respectively. These obtained data confirmed their tight relation to the Icosahedron structure (ICO) or the Frank-Kasper polyhedron structure of the bulk material 
[23]. In this direction, in 2009, Hoang [24] determined the relationship between crystalline temperature $\left(T_{g}\right)$ and the size $(D)$ of nano-Fe. He found that, with $D$ values $D=3.0,4.0$, and $5.0 \mathrm{~nm}, T_{g}$ values are $T_{g}=860,878$, and $909 \mathrm{~K}$, respectively. The author also argued that their energy $(E)$ and number of atoms $(N)$ had a certain relationship with each other. In 2015, Van [25] identified the structure and crystallization process of nano-Fe at a temperature $(T)$ of $T=300 \mathrm{~K}$ corresponding to annealing time $(t)$, through $2.5 \times 10^{7}$ steps of MD simulation. The authors indicated that after the annealing time at $T=300 \mathrm{~K}$, nano-Fe was in an amorphous state. In the case of Ni nanoparticles, several works identified their transition temperature $\left(T_{m}\right)$, which was always proportional to their number of atoms $(N), N^{-1 / 3}$ [26-31]. These authors reported that increasing atoms number $(\mathrm{N})$ (from $N=336$ to $N=8007$ atoms) increased their phase transition temperature $\left(T_{m}\right)$, from $T_{\mathrm{m}}=980 \mathrm{~K}$ to $T_{\mathrm{m}}=1380 \mathrm{~K}$ [26]. Similarly, Wen et al. confirmed that glass temperature $\left(T_{q}\right)$ of Ni nanowires was always proportional to their $D^{-1}$ value [27]. In recent years, we used the MD method for studying various metals and alloys, such as $\mathrm{Fe}$ [32-35], Ni [26-32, 36, 37], Ni alloy [38-42], and Al [43]. We found that the first peak position $(r)$ radial distribution function (RDF) of Fe metal is $r=2.55 \AA$, which is consistent with both the experimental results $[21,22]$ and other previous simulations $[18,19,21,22,25]$. In the case of biomedical applications, to enhance their biological compatibility, the core/shell hybrid nanostructure has been developed using nonmagnetic materials (gold, silver, and polymer) as the shells. In this case, a method for simulation of core/shell model has been used to identify structural characteristic quantities based on the formation of separate layers $[44,45]$. At present, there was a lack of the literature related to the factors influencing on structure of amorphous nano-Fe. To shed more light on this issue, in this study, we use the MD method with Sutton-Chen (SC) embedded interaction potential, the Verlet [46] algorithm, and free boundary conditions to research. The obtained results will serve as the basis for biomedical magnetic research in the future.

\section{Calculation Methods}

Initially, we randomly sowed these atoms Fe in spherical blocks with size $(D)$, as follows:

$$
D=2\left(\frac{3 N}{4 \pi \rho}\right),
$$

where density $\left(\rho=7.0 \mathrm{~g} \mathrm{~cm}^{-3}\right)$ and atoms numbers $(N)$ are obtained by the molecular dynamics (MD) method. The embedded interaction potential Sutten-Chen (SC) and free boundary conditions [47-50] can be calculated by the following equations:

$$
\begin{aligned}
E & =\sum_{i=1}^{N} \frac{1}{2} \sum_{j=1, j \neq 1}^{N} \Phi\left(r_{i j}\right)+F\left(\rho_{i}\right), \\
\Phi\left(r_{i j}\right) & =\varepsilon\left(\frac{a}{r_{i j}}\right)^{n}, \\
F\left(\rho_{i}\right) & =-\varepsilon C \sum_{i=1}^{N} \sqrt{\rho_{i}}, \\
\rho_{i} & =\sum_{j=1, j i}^{N} \rho\left(r_{i j}\right),
\end{aligned}
$$

where $\quad \varepsilon=0.017306 \mathrm{eV}, \quad a=3.471392 \AA, \quad C=24.939$, $m=4.7877, n=8.137381$, and $r_{\mathrm{c}}=3.35 \AA$ [26, 51].

Initially, we run the recovery statistics $1 \times 10^{4}$ steps NVT ( $N$ : number of atoms, volume: $V$, and temperature: $T$ at a constant value of $T=7000 \mathrm{~K}$ ) to nano-Fe existing in a liquid state, the atoms do not stick together. Thereafter, we decrease the temperature $(T)$ from $T=7000 \mathrm{~K}$ to $T=300 \mathrm{~K}$ to change the state of the material from liquid to amorphous ones with heating rate $\sim 1 \times 10^{6} \mathrm{~K} / \mathrm{s}$, and the time in each step of MD simulation is $0.46 \mathrm{fs}$.

The effect of various factors, such as number of atoms $(N$, $N=3000$ atoms: $\mathrm{Fe}_{3000}, N=4000$ atoms: $\mathrm{Fe}_{4000}, N=5000$ atoms: $\mathrm{Fe}_{5000}, N=10000$ atoms: $\mathrm{Fe}_{10000}, N=15000$ atoms: $\mathrm{Fe}_{15000}, \quad N=20000$ atoms: $\left.\mathrm{Fe}_{20000}\right)$, temperature (T, $T=300 \mathrm{~K})$, and pressure $(P, P=0.0 \mathrm{GPa})$, on the structure of amorphous nano-Fe have been evaluated. Besides, to study the effect of shell thickness ( $d=1 \AA$ to $d=2,3,4 \AA$ ) with $\mathrm{Fe}_{10000}$ at $T=300 \mathrm{~K}$ on the structure of amorphous nano-Fe, we run $1 \times 10^{5}$ steps NVE. On the studying structure of amorphous nano-Fe, we use the Verlet algorithm with the heating process (followed the laws of Nosé [52] and Hoover [53]). To determine the radial distribution function (RDF) of the amorphous nano-Fe, the X-ray diffraction method has been used for determining the structural factors. Then, the Fourier function has been used to calculate their structural factors [54-58]. Based on these data, their $g(r)$, radial distribution function (RDF) [59-64], is evaluated by using the statistical method as follows:

$$
g(r)=\frac{n(r)}{4 \pi r^{2} \mathrm{~d} r \rho_{0}} .
$$

Also, the coordination number $(\mathrm{CN})$ [65] can be calculated by using the following equation:

$$
\mathrm{CN}=4 \pi \rho \int_{0}^{R} g(r) r^{2} \mathrm{~d} r
$$

where $r$ is the cut radius (or the minimum position right after the first vertex of RDF). To check the accuracy of results, we use tools as the centrosymmetric parameter $[29,66]$, the bond angle analysis [67], the bond order analysis [68], and the AFM analysis method to find the morphology of surface [69] and fractal and multifractal geometric structures determined directly from the database [70]. 


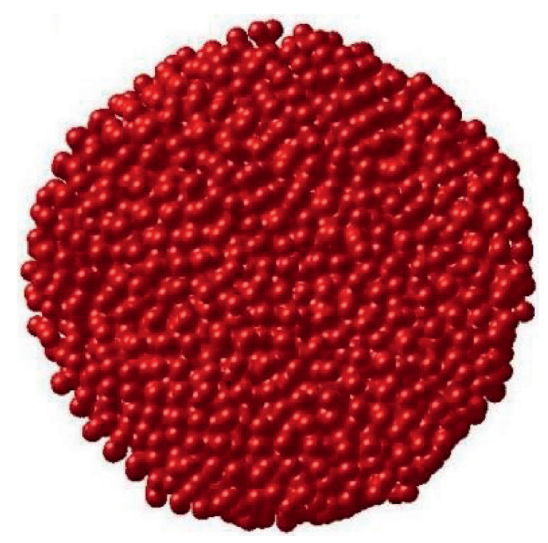

(a)

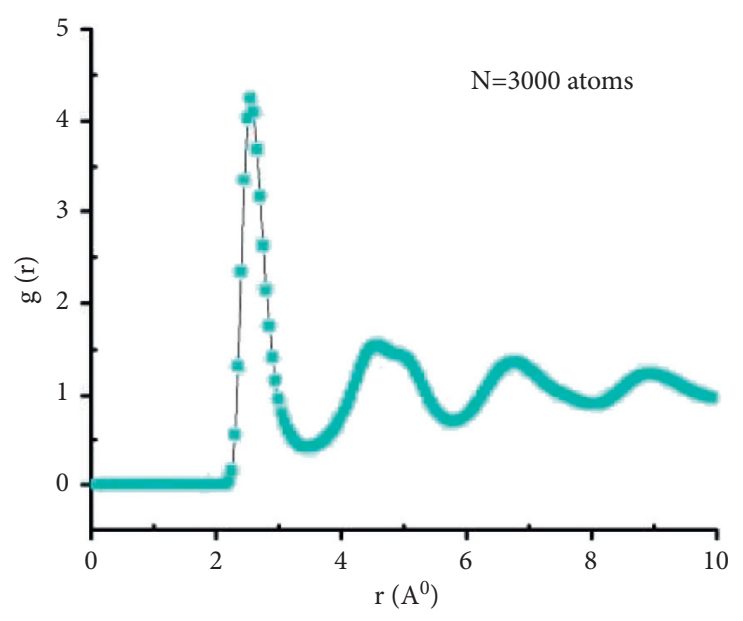

(b)

Figure 1: Shape (a) and radial distribution function RDF (b) of amorphous nano-Fe with number of atoms $N=3000$ atoms.

\section{Results and Discussion}

3.1. Effect of Number of Atoms. Figure 1 and Table 1 present the morphology and structure of amorphous nano-Fe with the different atomic numbers. As can be seen in Figure 1 and Table 1, the obtained results indicated that amorphous nano$\mathrm{Fe}$, with number of atoms $N=3000$ atoms $\left(\mathrm{Fe}_{3000}\right)$ at $T=300 \mathrm{~K}$, has the spherical shape. These $\mathrm{Fe}$ atoms are uniformly distributed, as seen as the red color in Figure 1(a), with size $(D=4.68 \mathrm{~nm})$ and energy $(E=-2.208 \mathrm{eV})$.

As shown in Figure 1(b), the first peak height of RDF, $g$ $(r)$, has the maximal value of $g(r)=4.242$ with the first peak position $(r)$ at $r=2.55 \AA$. When we increase atoms number (N) from $N=3000$ atoms to $N=4000,5000,10000,15000$, and 20000 atoms, size $(D)$ increases from $D=4.68 \mathrm{~nm}$ to $D=4.98,5.30,6.60,7.77$, and $8.39 \mathrm{~nm}$ and energy $(E)$ decreases from $E=-2.208 \mathrm{eV}$ to $E=-2.218,-2.234,-2.256$, -2.276 , and $-2.289 \mathrm{eV}$ whereas $r$ has a constant value of $r=2.55 \AA$ and $g(r)$ value varies from $g(r)=4.242$ to $g(r)$ $=4.141,4.162,4.170,4.241$, and 4.275 (Table 1), which does not follow the rule indicating far interaction of amorphous nano-Fe. This almost near interaction is consistent with reported results from experimental method $(r=2.54 \AA)$, Neutron method $(r=2.62 \AA)$, X-ray method $(r=2.57 \AA)$ $[2,21,22]$, and simulation method $(r=2.55 \AA)$ [18-20]. Figure 2 shows the relationship between size $(D)$ and energy $(E)$ with the number of atoms $(N)$ of amorphous nano-Fe.

As can be seen in Figure 2, the increase in number of atoms $\mathrm{N}$ leads to increasing size $D$ and decreasing energy $E$. Based on these data, the relationship between $D$ and $E$ with $N$ can be satisfied with the following formula. In case that $D=12.99-127.5 N^{-1 / 3} \quad(\mathrm{~nm})$ (Figure 2(a)), $E=2.209+0.004 N^{-1}(\mathrm{eV})$ (Figure 2(b)). Thus, in all cases, $D$ and $E$ are proportional to $N^{-1 / 3}$ and $N^{-1}$, respectively. These results match well with the published works, such as the phase transition temperature $T_{m}$ was proportional to atom number $N^{-1 / 3}[26,28,71,72]$ and to size $D^{-1}$ [27]. To confirm our findings, we select the $\mathrm{Fe}_{10000}$ nanoparticles amorphous at temperature $T=300 \mathrm{~K}$ to match the experimental data for cubic $\mathrm{Fe}$ at temperature $T=300 \mathrm{~K}$ with $r=2.52 \AA$ [21]. Figure 3 presents the simulation result.

As shown in Figure 3, the first peak position RDF of $\mathrm{Fe}_{10000}$ nanoparticles amorphous at temperature $T=300 \mathrm{~K}$ obtained by the MD method has $r=2.55 \AA$ consistent with the experimental data for Fe bulk material at $T=300 \mathrm{~K}$ with $r=2.52 \AA$ [21]. To further verify these results, we combine the visualized methods (Figure 4 and Table 2).

As seen, when increase in atoms numbers $N$ (from $N=3000$ atoms to $N=4000,5000,10000,15000,20000$ atoms) leads to $r$ has the constant values is $r=2.55 \AA$ and $g(r)$ increasing from $g(r)=4.242$ (Figure $4 \mathrm{a} 1$ ) to $g(r)=4.141$ (Figure 4a2), 4.162 (Figure 4a3), 4.170 (Figure 4a4), 4.241 (Figure 4a5), 4.246 (Figure 4a6), corresponding to shape of nanoparticle Fe amorphous (Figure 4b1, 4b2,.. 4b6) and coordination number $(\mathrm{CN})$ has to the constant valuesis $\mathrm{CN}=13$. Also, the density coordination number $\left(\mathrm{CN}_{d}\right)$ increases from $\mathrm{CN}_{d}=29.2 \%$ to $30,2 \%, 31.4 \%, 32.2 \%, 32.4 \%$, and $32.5 \%$ (Table 2). These data confirmed that the increase in $N$ leads to increasing the density of atoms, thus affecting the structure of amorphous nano-Fe, and the cause of this phenomenon is the size effect. The results obtained serve as the basis for experimental studies in future biomedical applications. We choose amorphous $\mathrm{Fe}_{10000}$ nanoparticles to study the influence of factors in the next section.

3.2. Effect of Crust Thickness. Besides the effect of atoms number, we evaluate also the effect of thickness factor on the structure of amorphous nano-Fe in its core/shell structure. Figure 5 shows the result for $\mathrm{Fe}_{10000}$ nanoparticles amorphous.

As can be seen in Figure 5(a), the core/shell shape of amorphous nano-Fe has its core (marked in red), shell (marked in blue), and the thickness $(d)$ of the shell layer. We assume that its atoms in the core are distributed evenly. Regarding the core radius $(R)$, when $R<28 \AA$ (Figure 5(b)), the local structural density $\rho(r)$ has an almost constant value 
TABLE 1: The size $(D)$, energy $(E)$, link length $(r)$, and height of first peak RDF $g(r)$ of Fe nanoparticles amorphous with various atoms number $N$.

\begin{tabular}{|c|c|c|c|c|c|c|}
\hline$N$ (atoms) & 3000 & 4000 & 5000 & 10000 & 15000 & 20000 \\
\hline$D(\mathrm{~nm})$ & 4.68 & 4.98 & 5.30 & 6.60 & 7.77 & 8.39 \\
\hline$E(\mathrm{eV})$ & -2.208 & -2.218 & -2.234 & -2.256 & -2.276 & -2.289 \\
\hline$r(\AA)$ & 2.55 & 2.55 & 2.55 & 2.55 & 2.55 & 2.55 \\
\hline$g(r)$ & 4.242 & 4.141 & 4.162 & 4.170 & 4.241 & 4.275 \\
\hline
\end{tabular}

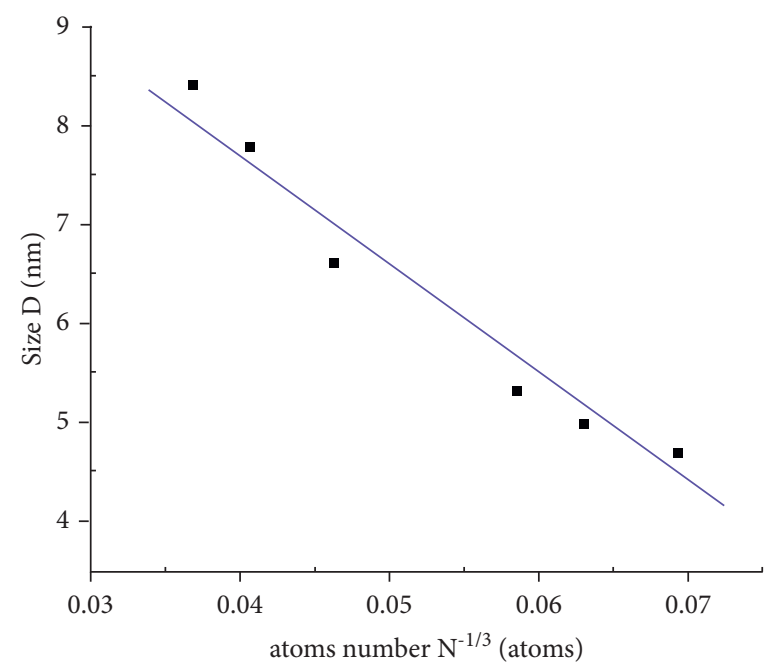

(a)

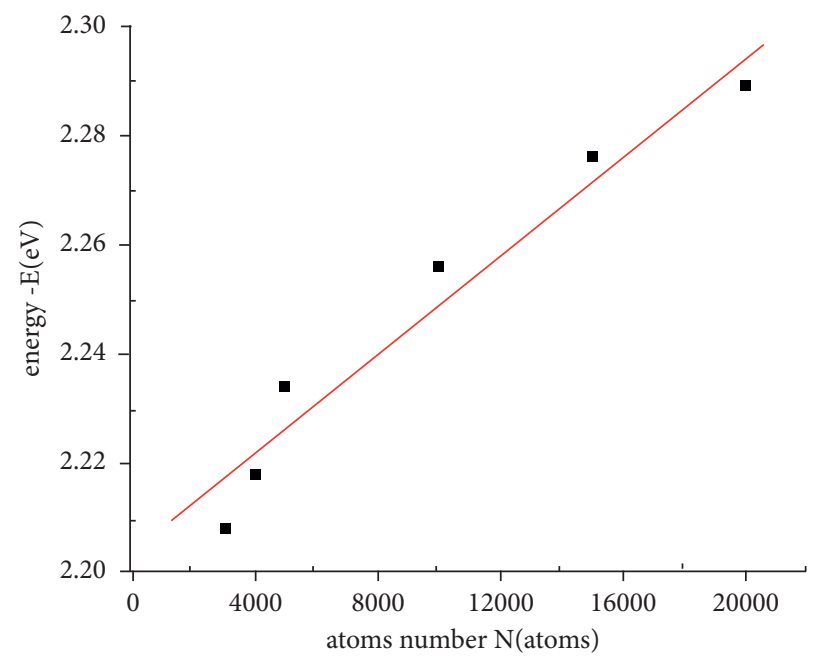

(b)

Figure 2: Relationship between size $(D)$ with number of atoms $(N)$ of amorphous nano-Fe (a) and relationship between energy $(E)$ with number of atoms $(N)$ of amorphous nano-Fe (b).

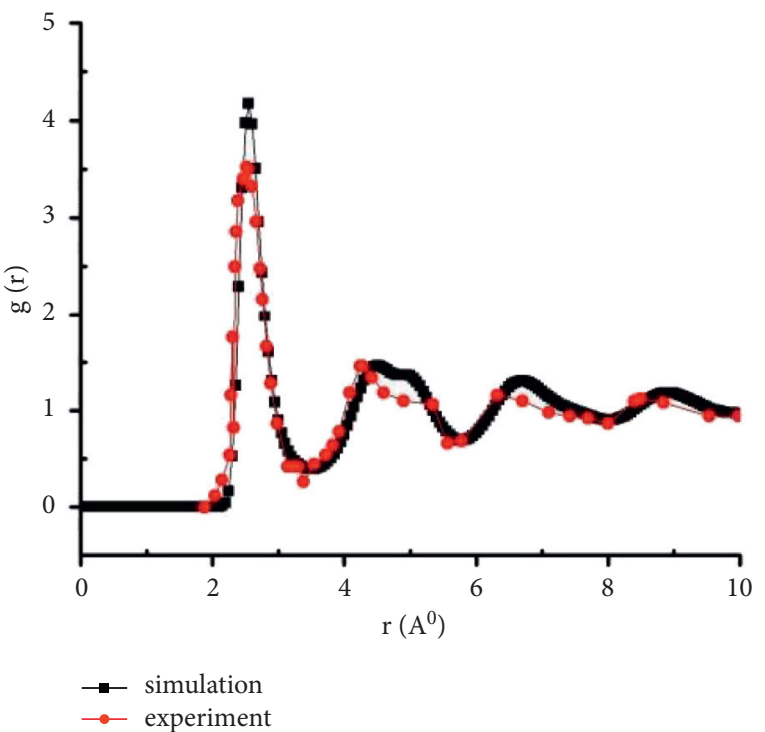

FIgURE 3: Coherence between the radial distribution function of $\mathrm{Fe}_{10000}$ nanoparticles amorphous by the simulation method and the experimental data of cubic Fe at temperature $T=300 \mathrm{~K}$.

of 0.0825 atoms $/ \AA^{3}$ (distributing evenly from the core layer to the shell). However, when $R>28 \AA$, the local structural density $\rho(r)$ reduces strongly (Figure $5(\mathrm{~b}))$. In this case, when the thickness of the shell $(d)$ is $5 \AA$ (Figure $5(b))$, the core exhibits a dense phase, while the shell presents porous structure. To confirm this result, we combine the shape, radial distribution function $\mathrm{RDF}$, coordination number $\mathrm{CN}$, and the visualized method as shown in Figure 6 and Table 3. 


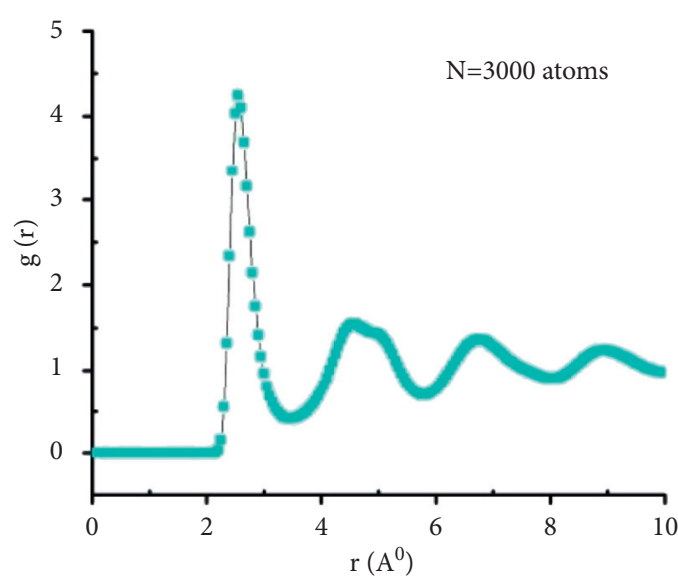

(a1)

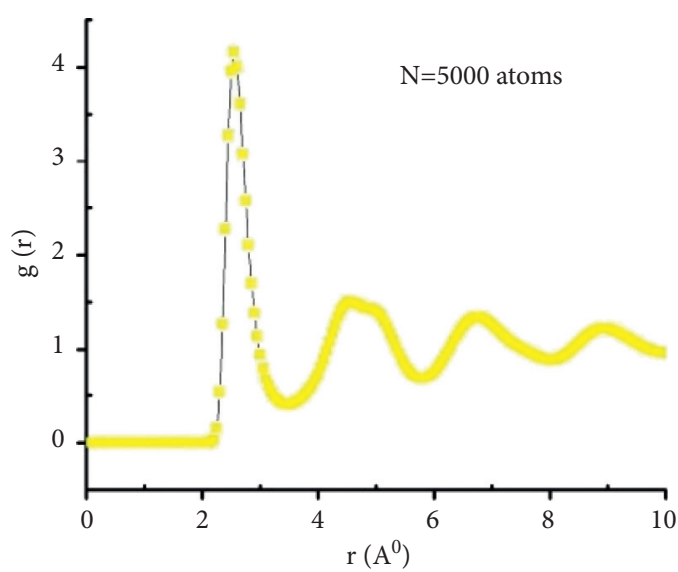

(a3)

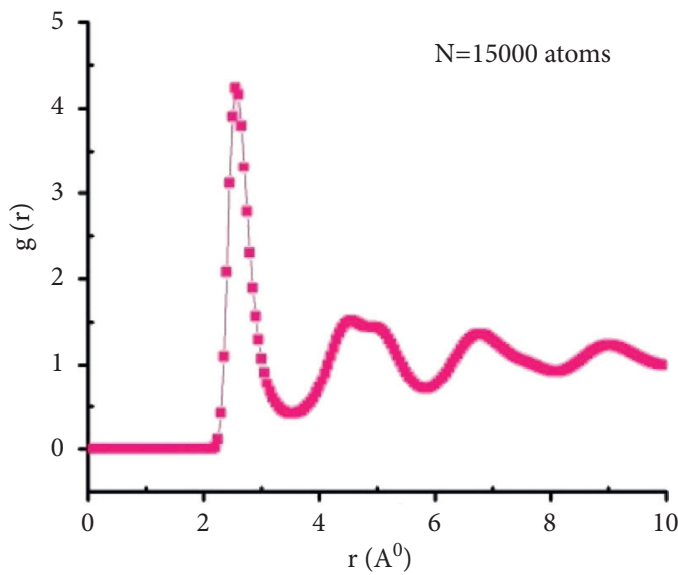

(a5)

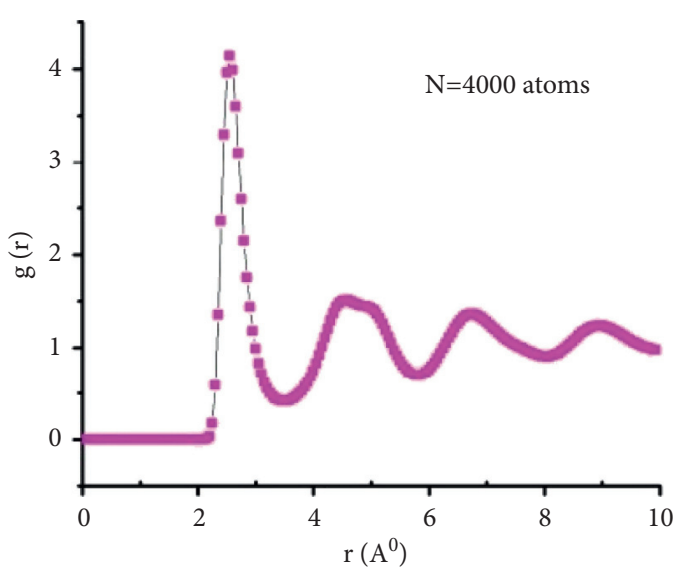

(a2)

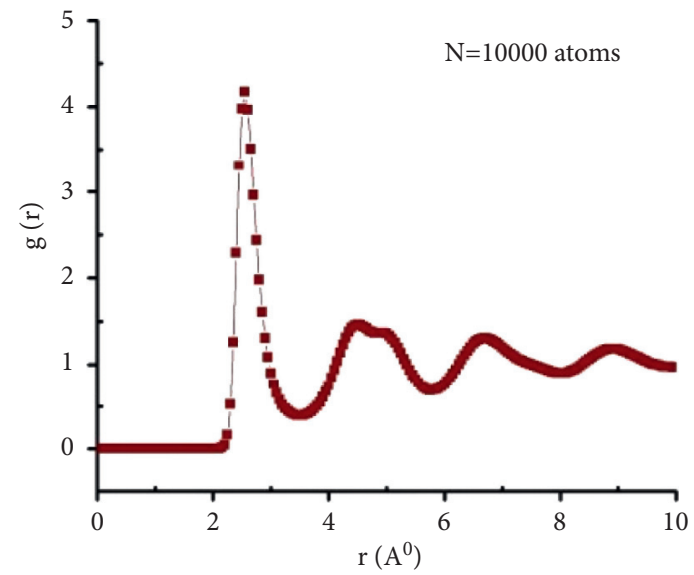

(a4)

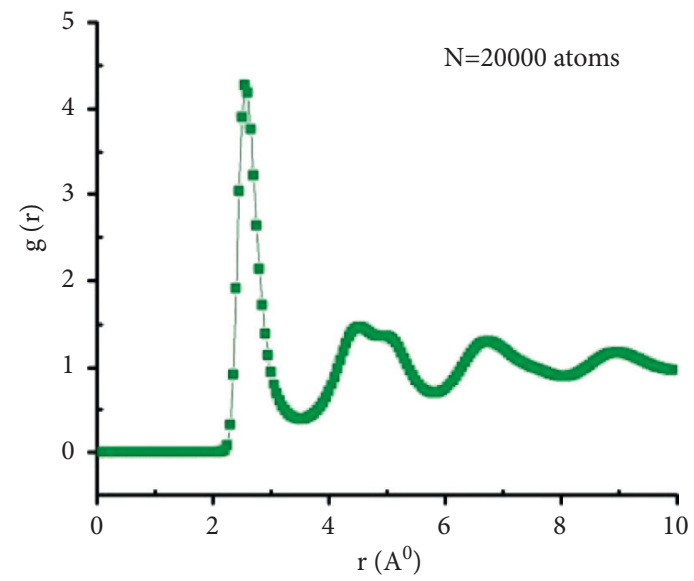

(a6)

(a)

Figure 4: Continued. 


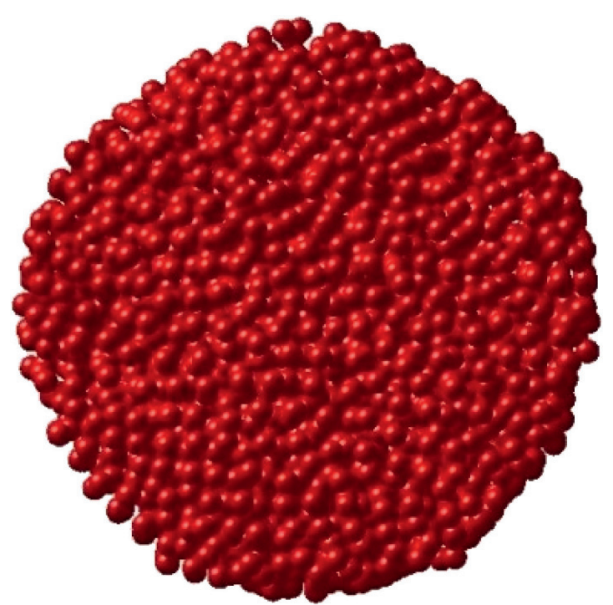

(b1)

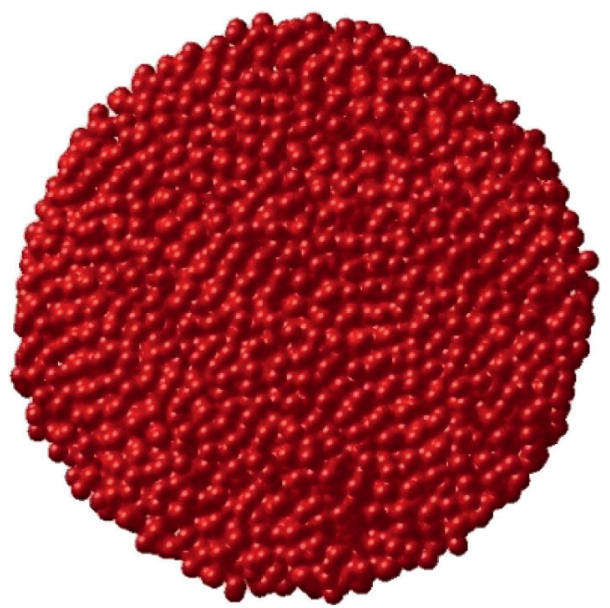

(b3)

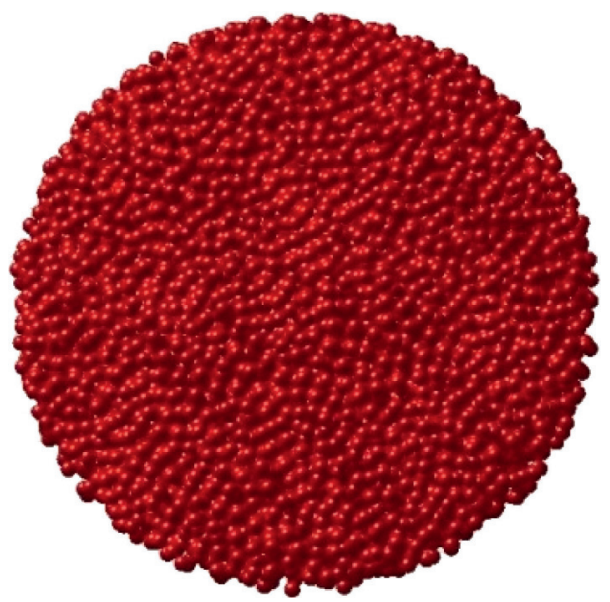

(b5)

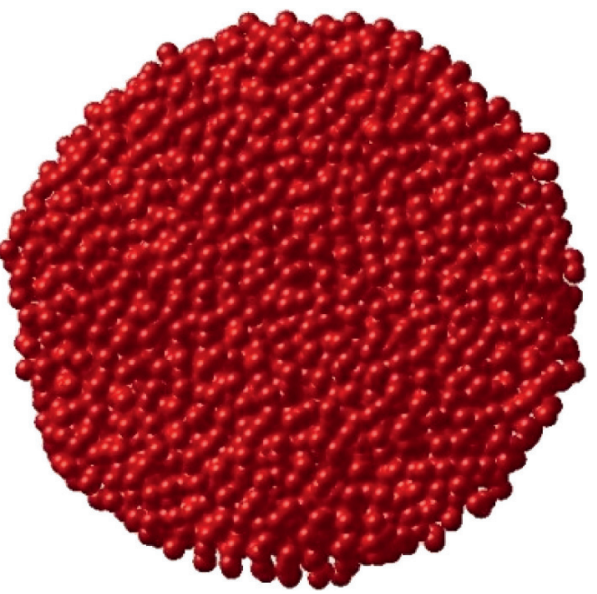

(b2)

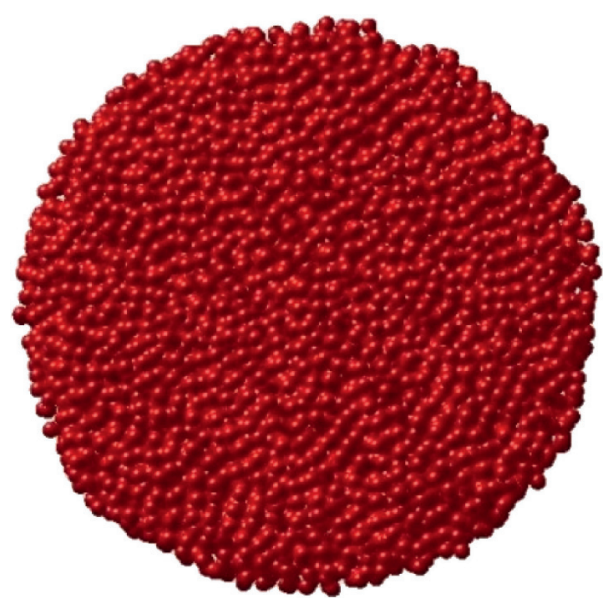

(b4)

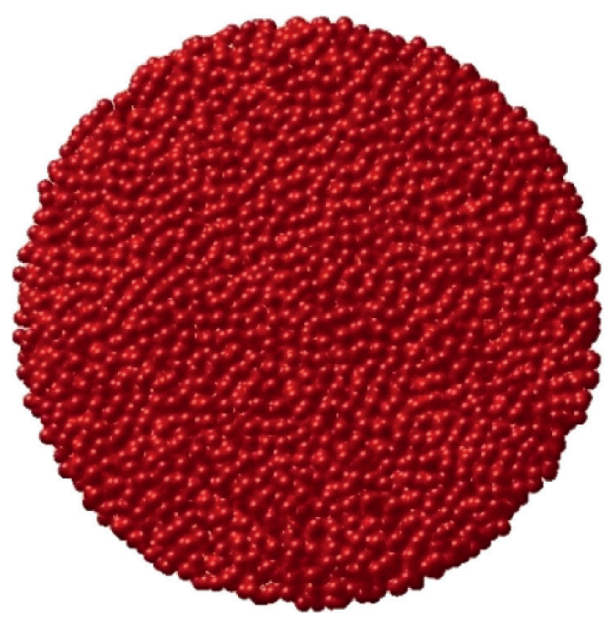

(b6)

(b)

Figure 4: The radial distribution function (a) (a1, a2, . . a6) and shape (b) (b1, b2, . b6) of amorphous Fe nanoparticles with various atoms numbers.

As shown in Figure 6, with the thickness of shell $(d)$, $d=1 \AA$, the respective values of $r, g(r), \mathrm{CN}$, and $\mathrm{CN}_{d}$ are $2.55 \AA, 3.907,13$, and $32.24 \%$. Then, the increase in $d$ values (from $d=1 \AA$ to $d=2,3,4 \AA$ ) leads to changing the shape of the Fe nanoparticles amorphous, the coordination number $\mathrm{CN}$ has value constant $\mathrm{CN}=13$, the coordination number 
TABLE 2: Coordination number $(\mathrm{CN})$ and coordination number density $(\mathrm{CNd})$ of amorphous Fe nanoparticles with different number of atoms.

\begin{tabular}{lccccc}
\hline Atoms numbers $N$ (atoms) & 3000 & 4000 & 5000 & 10000 & 15000 \\
\hline Coordination number CN & 13 & 13 & 13 & 13 & 13 \\
Coordination number density $\mathrm{CN}_{d}(\%)$ & 29.2 & 30.2 & 31.4 & 32.2 & 13 \\
\hline
\end{tabular}

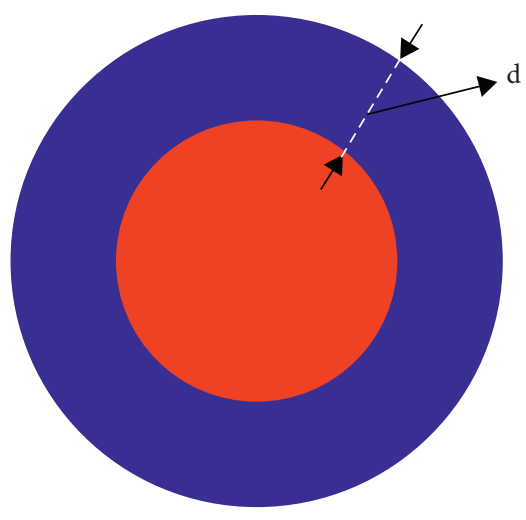

(a)

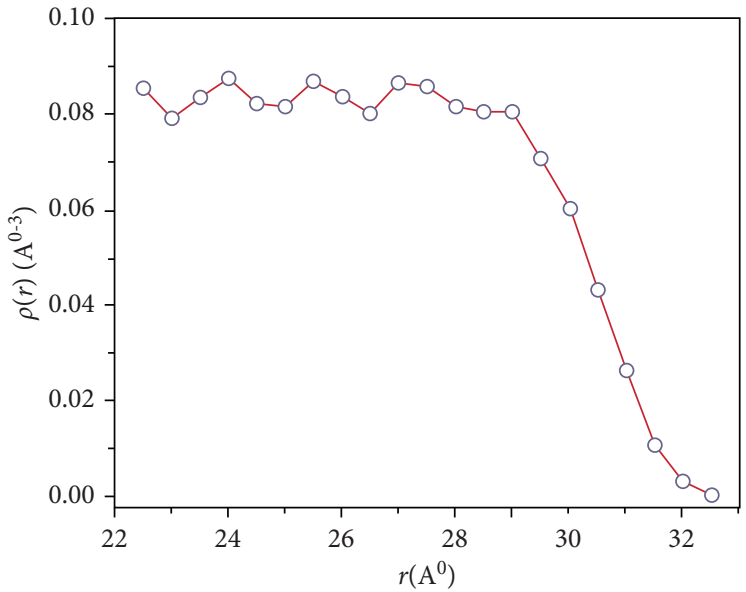

(b)

Figure 5: Shape (a) and local structure (b) of core/shell nano-Fe $\mathrm{F}_{10000}$ amorphous.

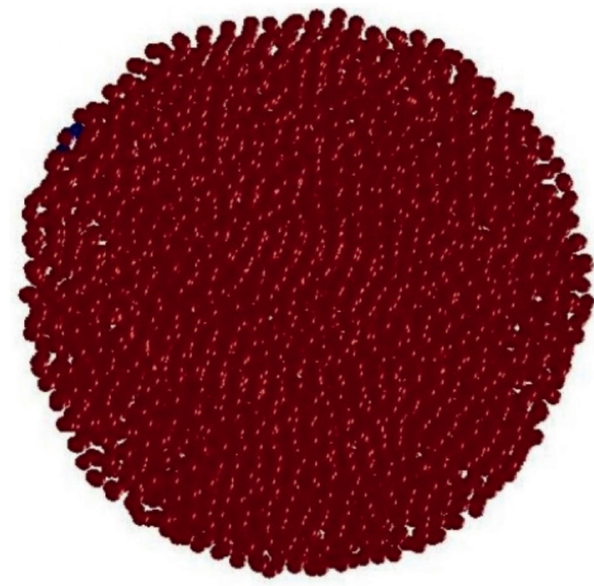

(a1)

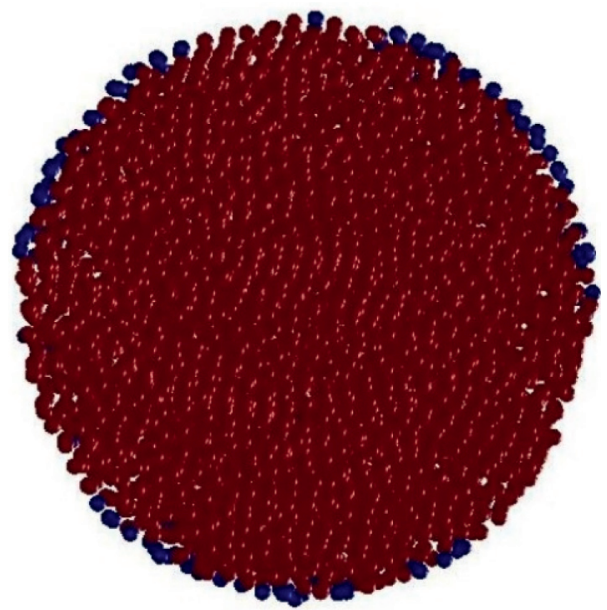

(b1)

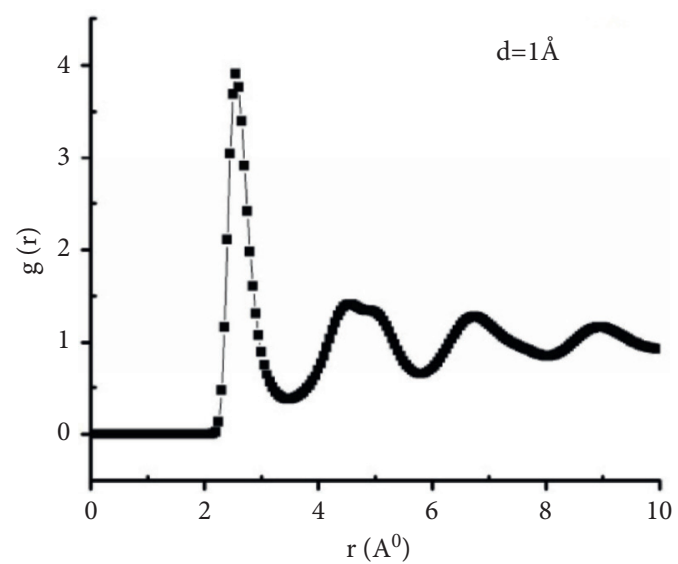

(a2)

(a)

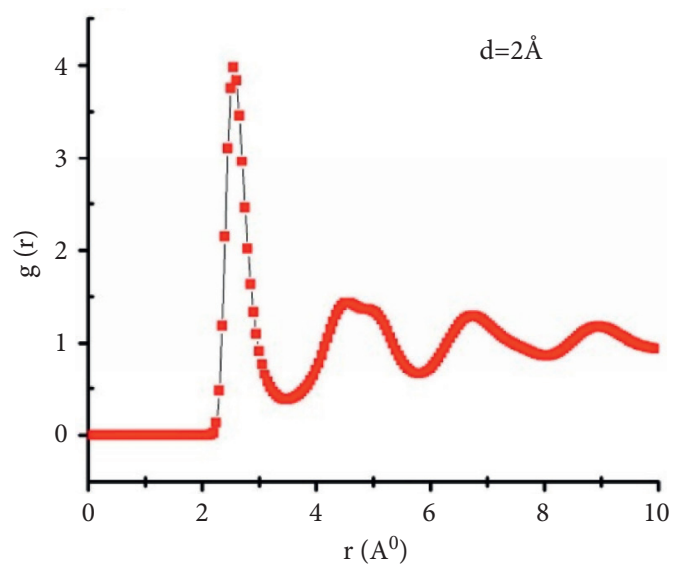

(b2)

(b)

Figure 6: Continued. 


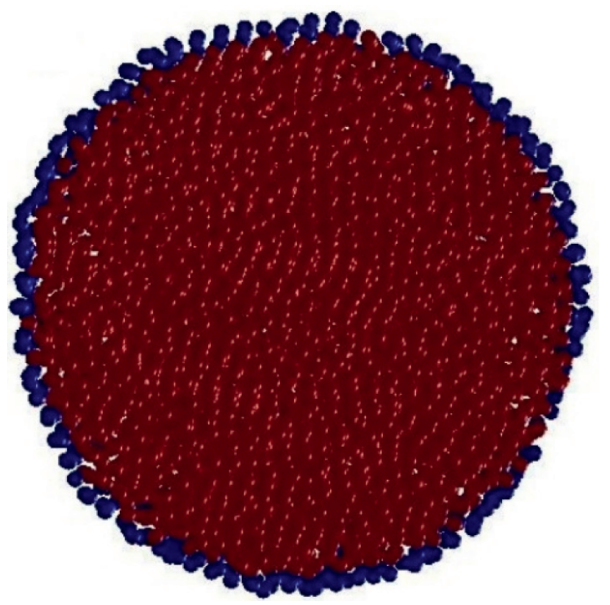

(c1)

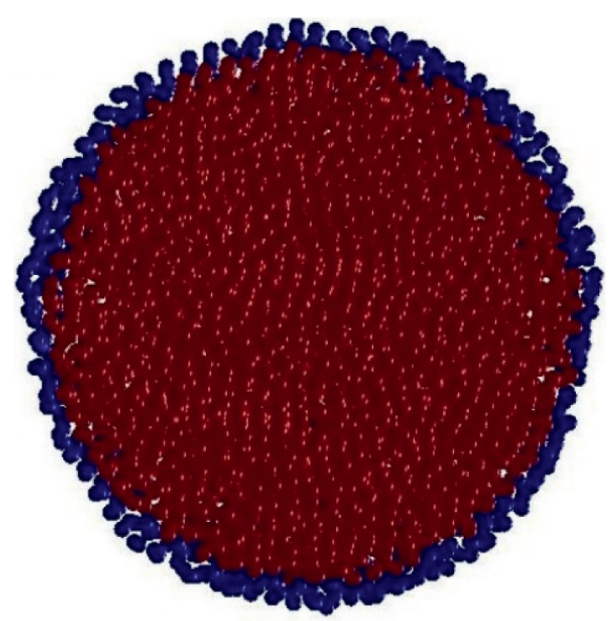

(d1)

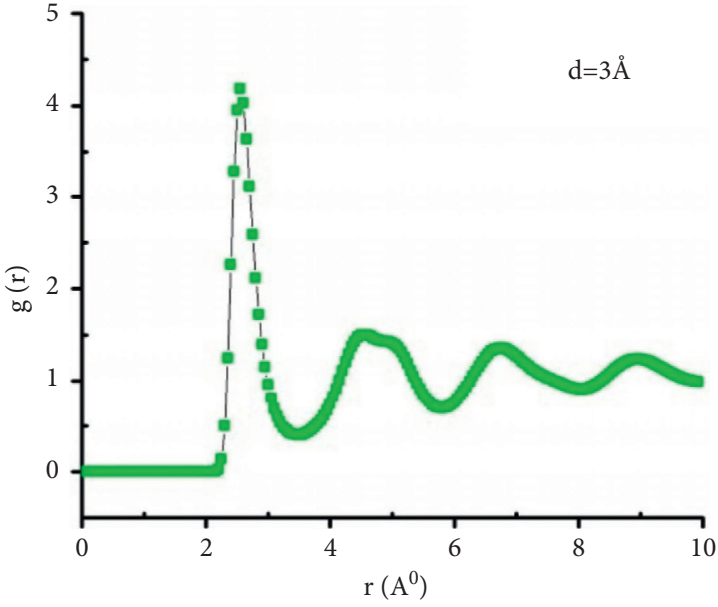

(c2)

(c)

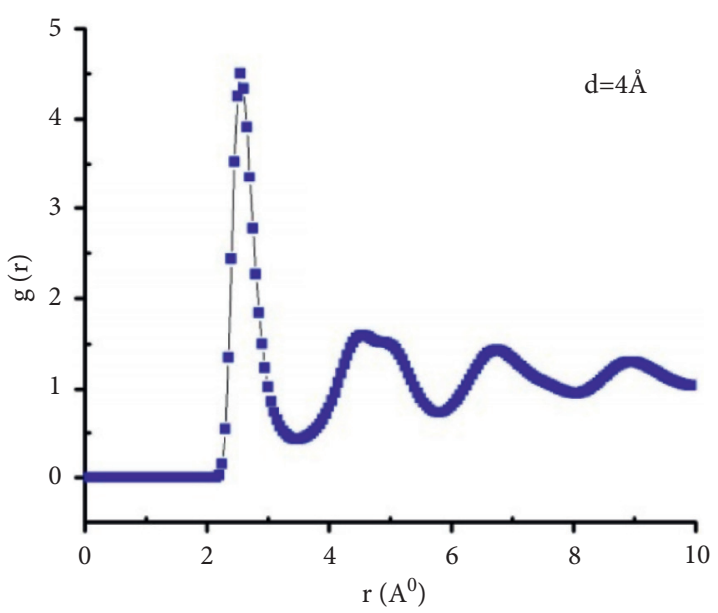

(d2)

(d)

FIgURE 6: Shape (a) (a1, b1, c1, and d1) and radial distribution function RDF (b) (a2, b2, c2, and d2) of amorphous Fe nanoparticles with various crust thicknesses.

density $\mathrm{CN}_{d}$ increases from $32.4 \%$ to $32.5 \%$ and increases $g$ ( $r$ ) (from 4.19 to $4.23,4.32,4.46$, and 4.51 ). However, by increasing $d$, the constant values of $r$ and $\mathrm{CN}$ are observed at $2.55 \AA$ and values, respectively, while $g(r)$ and $\mathrm{CN}_{d}$ increasing. An interesting result is that the coordination number density of the shell is smaller than that of the core (the core is in a dense structure).

3.3. Influence of Temperature. Along with the influence of both atom numbe0r and shell thickness, temperature also affects the structure of amorphous nano-Fe. Figure 7 and Table 4 present the obtained data for $\mathrm{Fe}_{10000}$ nanoparticles amorphous at various temperatures $(T)$ from $T=300 \mathrm{~K}$ to $T=500,700,800,900,1000$, and $1100 \mathrm{~K}$.

As shown in Figure 7 , at temperatures $T=300 \mathrm{~K}$, the results show that $\mathrm{Fe}_{10000}$ nanoparticles amorphous have spherical shape with size $D=6.6 \mathrm{~nm}$, energy $E=-2.256 \mathrm{eV}$, link length $r=2.55 \AA$, height of first peak RDF $g(r)=4.18$, coordination number $\mathrm{CN}=13$, and coordination number density $\mathrm{CN}_{d}=30.72 \%$. However, the increase in temperatures $T$ from $300 \mathrm{~K}$ to $500,700,800,900,1000$, and $1100 \mathrm{~K}$ leads to increasing $E$ (from $-2.256 \mathrm{eV}$ to $-2.192,-2.121$, $-2.083,-2.065,-2.018$, and $-1.991 \mathrm{eV}$ ), decreasing $r$ (from $2.55 \AA$ to $2.55,2.55,2.55,2.55,2.5$, and $2.5 \AA$ ), decreasing $g$ (r) (from 4.18 to and 2.26), decreasing CN (from 13 to 13, 13, $13,13,12$, and 12), and decreasing $\mathrm{CN}_{d}$ from $32.2 \%$ to 30.2 , $28.25,25.43,26.74,25.85$, and 24.94\% (Table 4).

In the case of $D$ value, it keeps a constant value of $D=6.6 \mathrm{~nm}$ when increasing $T$. Figure 8 presents the relationship between energy $(E)$ and temperature $(T)$. As shown in Figure 8, the increase in $T$ value (from $300 \mathrm{~K}$ to $500,700,800$, $900,1000$, and $1100 \mathrm{~K})$ leads to increasing energy $E(-2.256 \mathrm{eV}$ to $-1.991 \mathrm{eV}$ ). Regarding the temperature range from $T=800 \mathrm{~K}$ to $T=1000 \mathrm{~K}$, the energy of $\mathrm{Fe}_{10000}$ nanoparticles amorphous significant changes, corresponding to the crystallization 
TABLE 3: Coordination number and coordination number density of amorphous Fe nanoparticles with various crust thicknesses.

\begin{tabular}{|c|c|c|c|c|}
\hline Thicknesses $d(\AA)$ & 1 & 2 & 3 & 4 \\
\hline Coordination number $\mathrm{CN}$ & 13 & 13 & 13 & 13 \\
\hline Coordination number density $\mathrm{CN}_{d}(\%)$ & 32.24 & 32.30 & 32.40 & 32.50 \\
\hline
\end{tabular}

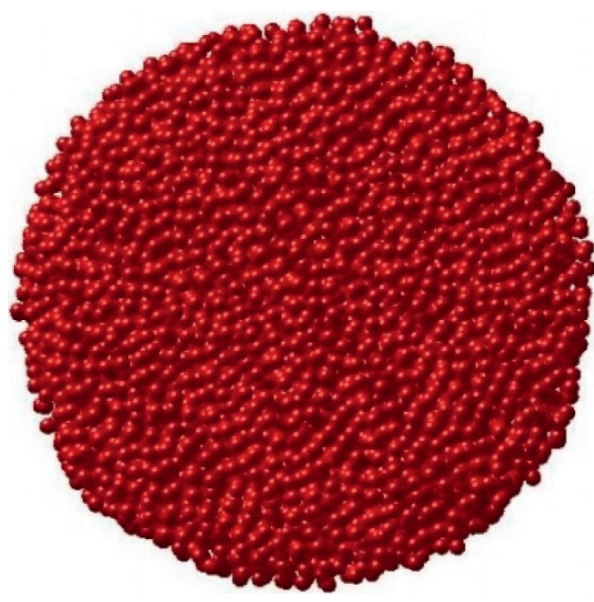

(a)

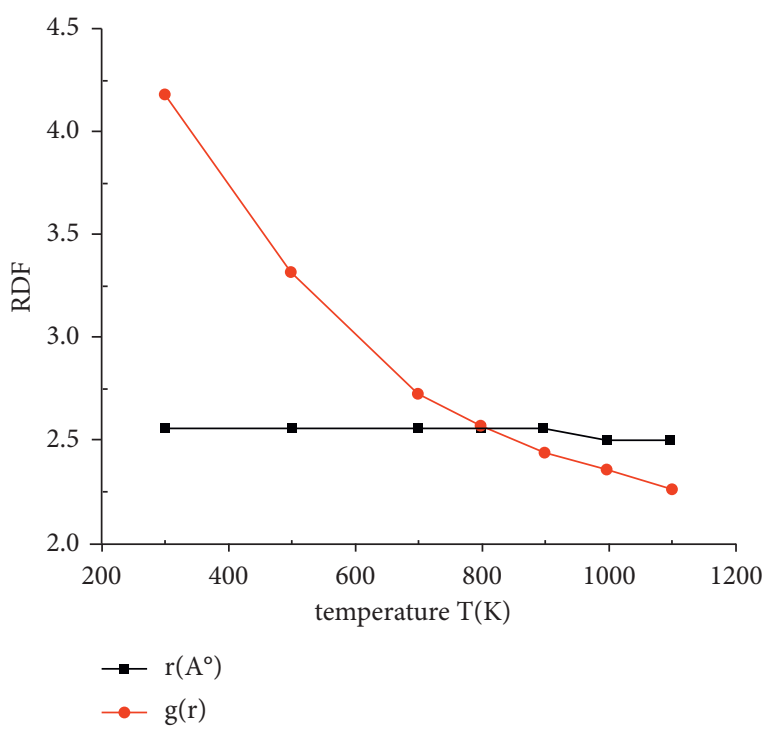

(b)

Figure 7: Shape of amorphous $\mathrm{Fe}_{10000}$ nanoparticles at temperatures $T=300 \mathrm{~K}$ (a) and radial distribution function RDF (b) of amorphous $\mathrm{Fe}_{10000}$ nanoparticles at different temperatures (from $T=300 \mathrm{~K}$ to $T=1100 \mathrm{~K}$ ).

TABLE 4: Coordination number and coordination number density of amorphous Fe nanoparticles with different temperatures.

\begin{tabular}{|c|c|c|c|c|c|c|c|}
\hline Temperatures $T(\mathrm{~K})$ & 300 & 500 & 700 & 800 & 900 & 1000 & 1100 \\
\hline Energy $E(\mathrm{eV})$ & -2.256 & -2.192 & -2.121 & -2.083 & -2.065 & -2.018 & -1.991 \\
\hline Coordination number $\mathrm{CN}$ & 13 & 13 & 13 & 13 & 13 & 12 & 12 \\
\hline Coordination number density $\mathrm{CN}_{d}(\%)$ & 32.20 & 30.20 & 28.25 & 25.43 & 26.74 & 25.85 & 24.94 \\
\hline
\end{tabular}

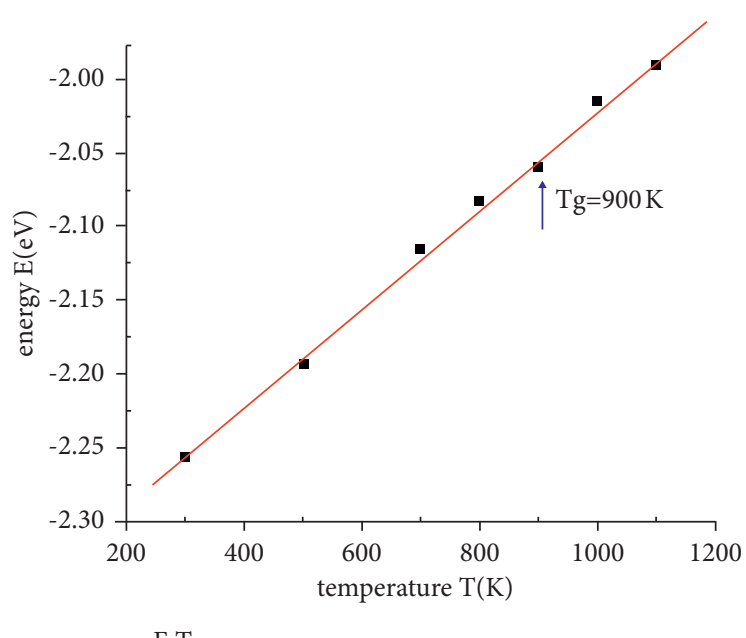

FIGURE 8: Relationship between energy and temperature of amorphous $\mathrm{Fe}_{10000}$ nanoparticles.

phenomenon $\left(T_{g}\right)$ at $T=900 \mathrm{~K}$ (glass temperature, $T_{g}=900 \mathrm{~K}$, corresponding with $E=-2.065 \mathrm{eV})$. The result obtained that $T_{\mathrm{g}}=900 \mathrm{~K}$ is completely consistent with the Curie phase transition temperature $\left(T_{c}\right)$ [34] and glass transition temperature $T_{g}$ [71], which shows that, with amorphous Fe nanoparticles, $T_{g}=T_{c}$ and there was no sudden increase in energy at 
the crystallization phase transition. The reason is that, with very small heating rate, the Fe nanoparticles gradually transit from the amorphous state to the liquid state and vice versa. These results are quite interesting. The results obtained are basis for future experimental studies to use amorphous Fe nanoparticles in magnetic applications.

\section{Conclusion}

The molecular dynamics (MD) method successfully indicates that amorphous nano-Fe exhibits the potential embedded Sutton-Chen (SC) and free boundary conditions. The obtained results show that the first peak position $(r)$ of the radial distribution function (RDF) has the value $r=2.55 \AA$, which is consistent with the published data from the experimental method, Neutron method, X-ray method, and another simulation method. The size $(D)$ and energy $(E)$ of amorphous nano-Fe are proportional to the atoms number $N^{-1 / 3}$ and $N^{-1}$, respectively. The obtained data for radial distribution function (RDF), coordination number $(\mathrm{CN})$, and density coordination number $\left(\mathrm{CN}_{d}\right)$ are all consistent with the published works by simulation and experimental studies. Amorphous nano-Fe at temperature (T) $T=300 \mathrm{~K}$ has the amorphous structure (with $\mathrm{CN}=13$ ), in which the increase in $D$ value leads to decreasing energy $(E)$. The molecular dynamics method for the core/shell $\mathrm{Fe}_{10000}$ nanoparticles amorphous indicates the core layer (with radius $r<28 \AA$ ) in dense structure, while the shell layer is in the porous structure. In addition, identified glass temperature $\left(T_{g}\right), T_{g}=900 \mathrm{~K}$, result obtained completely consistent with the Curie phase transition temperature $\left(T_{c}\right)$, which shows that, with amorphous $\mathrm{Fe}$ nanoparticles, $T_{g}=T_{c}=900 \mathrm{~K}$, and this is quite interesting and interesting results basis for future experimental studies.

\section{Data Availability}

The data that support the findings of this study are available from the corresponding author upon reasonable request.

\section{Conflicts of Interest}

The authors declare that they have no conflicts of interest.

\section{References}

[1] B. L. Bramfitt and A. O. Benscoter, "Metallographer's guide: practice and procedures for irons and steels," ASM International, vol. 170, 2002.

[2] S. P. Gubin, Y. A. Koksharov, G. B. Khomutov, and G. Y. Yurkov, "Magnetic nanoparticles: preparation, structure and properties," Russian Chemical Reviews, vol. 74, no. 6, pp. 489-520, 2005.

[3] S. D. Bader, "Colloquium: opportunities in nanomagnetism," Reviews of Modern Physics, vol. 78, no. 1, pp. 1-15, 2006.

[4] J. Kim, S. Park, J. E. Lee et al., "Designed fabrication of multifunctional magnetic gold nanoshells and their application to magnetic resonance imaging and photothermal therapy," Angewandte Chemie International Edition, vol. 45, no. 46, pp. 7754-7758, 2006.
[5] A.-H. Lu, W. Schmidt, N. Matoussevitch et al., "Nanoengineering of a magnetically separable hydrogenation catalyst," Angewandte Chemie International Edition, vol. 43, no. 33, pp. 4303-4306, 2004.

[6] S. Nie, "Probing single molecules and single nanoparticles by surface-enhanced Raman scattering," Science, vol. 275, no. 5303, pp. 1102-1106, 1997.

[7] G. V. Kurlyandskaya, M. L. Sánchez, B. Hernando, V. M. Prida, P. Gorria, and M. Tejedor, "Giant-magnetoimpedance-based sensitive element as a model for biosensors," Applied Physics Letters, vol. 82, no. 18, pp. 3053-3055, 2003.

[8] J. Rivas, M. Bañobre-López, Y. Piñeiro-Redondo, B. Rivas, and M. A. López-Quintela, "Magnetic nanoparticles for application in cancer therapy," Journal of Magnetism and Magnetic Materials, vol. 324, no. 21, pp. 3499-3502, 2012.

[9] Q. A. Pankhurst, J. Connolly, S. K. Jones, and J. Dobson, "Applications of magnetic nanoparticles in biomedicine," Journal of Physics D: Applied Physics, vol. 36, no. 13, pp. R167-R181, 2003.

[10] C. Alexiou, A. Schmidt, R. Klein, P. Hulin, C. Bergemann, and W. Arnold, "Magnetic drug targeting: biodistribution and dependency on magnetic field strength," Journal of Magnetism and Magnetic Materials, vol. 252, pp. 363-366, 2002.

[11] A. Jordan, "Hyperthermia classic commentary: 'inductive heating of ferrimagnetic particles and magnetic fluids: physical evaluation of their potential for hyperthermia' by Andreas Jordan et al.,international journal of hyperthermia, 1993;9:51-68," International Journal of Hyperthermia, vol. 25, no. 7, pp. 512-516, 2009.

[12] F. Michael, C. Gonzalez, V. Mujica, M. Marquez, and M. A. Ratner, "Size dependence of ferromagnetism in gold nanoparticles: mean field results," Physical Review B, vol. 76, no. 22, Article ID 224409, 2007.

[13] H. Kachkachi, "Effects of spin non-collinearities in magnetic nanoparticles," Journal of Magnetism and Magnetic Materials, vol. 316, no. 2, pp. 248-254, 2007.

[14] A. Zaim and M. Kerouad, "Monte Carlo simulation of the compensation and critical behaviors of a ferrimagnetic core/ shell nanoparticle Ising model," Physica A: Statistical Mechanics and Its Applications, vol. 389, no. 17, pp. 3435-3442, 2010.

[15] Y. Yüksel, E. Aydıner, and H. Polat, "Thermal and magnetic properties of a ferrimagnetic nanoparticle with spin-3/2 core and spin-1 shell structure," Journal of Magnetism and Magnetic Materials, vol. 323, no. 23, pp. 3168-3175, 2011.

[16] L. Jiang, J. Zhang, Z. Chen, Q. Feng, and Z. Huang, "Monte Carlo study of magnetic properties for the mixed spin-3/2 and spin-1 ferrimagnetic nanoparticles," Physica B: Condensed Matter, vol. 405, no. 1, pp. 420-424, 2010.

[17] B. Deviren, M. Keskin, and Y. Aydin, "Compensation temperatures, magnetic susceptibilities and phase diagrams of a mixed ferrimagnetic ternary system on the Bethe lattice," JETP Letters, vol. 92, no. 4, pp. 214-222, 2010.

[18] P. K. Leung and J. G. Wright, "Structural investigations of amorphous transition element films: II. chromium, iron, manganese and nickel," Philosophical Magazine, vol. 30, no. 5, pp. 995-1008, 1974.

[19] V. Van Hoang and N. H. Cuong, "Local icosahedral order and thermodynamics of simulated amorphous Fe," Physica B: Condensed Matter, vol. 404, no. 2, pp. 340-346, 2009.

[20] P. W. Ma, S. L. Dudarev, A. A. Semenov, and C. H. Woo, “Temperature for a dynamic spin ensemble," Physical review. 
E, Statistical, nonlinear, and soft matter physics, vol. 82, Article ID 031111, 2010.

[21] T. Ichikawa, "Electron diffraction study of the local atomic arrangement in amorphous iron and nickel films," Physica Status Solidi A, vol. 19, no. 2, pp. 707-716, 1973.

[22] J.-P. Lauriat, "Study by X-ray and neutron diffraction of the structure of Ex-carbonyl amorphous iron," Journal of Noncrystalline Solids, vol. 55, no. 1, pp. 77-91, 1983.

[23] D. Caruntu, G. Caruntu, and C. J. O’Connor, "Magnetic properties of variable-sized $\mathrm{Fe} 3 \mathrm{O} 4$ nanoparticles synthesized from non-aqueous homogeneous solutions of polyols," Journal of Physics D: Applied Physics, vol. 40, no. 19, pp. 5801-5809, 2007.

[24] V. V. Hoang, "Molecular dynamics simulation of liquid and amorphous Fe nanoparticles," Nanotechnology, vol. 20, no. 7, p. 295703, 2009.

[25] H. H. Van, "Crystallization of amorphous iron nanoparticles by means of molecular dynamics simulation," International Journal of Nano Studies \& Technology, vol. 4, no. 3, pp. 88-92, 2015.

[26] Y. Qi, T. Çağin, W. L. Johnson, and W. A. Goddard III, "Melting and crystallization in Ni nanoclusters: the mesoscale regime," The Journal of Chemical Physics, vol. 115, no. 1, pp. 385-394, 2001.

[27] Y.-H. Wen, Z.-Z. Zhu, R. Zhu, and G.-F. Shao, "Size effects on the melting of nickel nanowires: a molecular dynamics study," Physica E: Low-Dimensional Systems and Nanostructures, vol. 25, no. 1, pp. 47-54, 2004.

[28] Y. Zhang, L. Wang, and W. Wang, "Thermodynamic, dynamic and structural relaxation in supercooled liquid and glassy Ni below the critical temperature," Journal of Physics: Condensed Matter, vol. 19, Article ID 196106, 2007.

[29] C. L. Kelchner, S. J. Plimpton, and J. C. Hamilton, "Dislocation nucleation and defect structure during surface indentation," Physical Review B, vol. 58, no. 17, pp. 11085-11088, 1998.

[30] A. N. Andriotis, Z. G. Fthenakis, and M. Menon, "Correlated variation of melting and Curie temperatures of nickel clusters," Physical Review B: Condensed Matter, vol. 75, Article ID 073413(4), 2007.

[31] C. S. Tian, D. Qian, D. Wu et al., "Body-centered-cubic Ni and its magnetic properties," Physical Review Letters, vol. 94, Article ID 137210, 2005.

[32] T. D. Nguyen, C. C. Nguyen, and V. H. Tran, "Molecular dynamics study of microscopic structures, phase transitions and dynamic crystallization in Ni nanoparticles," RSC Advances, vol. 7, no. 41, pp. 25406-25413, 2017.

[33] P. H. Kien, M. T. Lan, N. T. Dung, and P. K. Hung, "Annealing study of amorphous bulk and nanoparticle iron using molecular dynamics simulation," International Journal of Modern Physics B, vol. 28, no. 23, Article ID 1450155, 2014.

[34] T. D. Nguyen, C. C. Nguyen, T. T. Nguyen, and K. H. Pham, "Factors on the magnetic properties of the iron nanoparticles by classical heisenberg model," Physica B: Condensed Matter, vol. 532, pp. 144-148, 2018.

[35] T. D. Nguyen and C. C. Nguyen, "Influence of the particle size on the microstructure and the curie temperature (TC) of nano-iron particles model," International Journal of Soft Computing and Engineering, vol. 6, no. 4, pp. 26-31, 2016.

[36] T. D. Nguyen and K. H. Pham, "The influence of particle size, the rate of heat on magnetic characteristic quantities and Tc curie phase transition temperature of the Ni nanoparticles by the classical heisenberg model," International Journal of Engineering \& Technology, vol. 7, no. 3.19, pp. 113-118, 2018.
[37] T. D. Nguyen and C. C. Nguyen, "Some factors affected on structure, mechanical of Ni bulk," Advances in Materials Physics and Chemistry, vol. 8, pp. 177-192, 2018.

[38] D. Nguyen-Trong, K. Pham-Huu, and P. Nguyen-Tri, "Simulation on the factors affecting the crystallization process of FeNi alloy by molecular dynamics," ACS Omega, vol. 4, no. 11, pp. 14605-14612, 2019.

[39] N.-T. Dung and N.-T. Phuong, "Factors affecting the structure, phase transition and crystallization process of $\mathrm{AlNi}$ nanoparticles," Journal of Alloys and Compounds, vol. 812, Article ID 152133, 2020.

[40] T. D. Nguyen, "Influence of impurity concentration, atomic number, temperature and tempering time on microstructure and phase transformation of $\mathrm{Ni}_{1-\mathrm{x}} \mathrm{Fe}_{\mathrm{x}}(\mathrm{x}=0: 1,0.3,0.5)$ nanoparticles," Modern Physics Letters B, vol. 32, no. 18, Article ID 1850204, 2018.

[41] Q. T. Tran and T. D. Nguyen, "Effect of heating rate, impurity concentration of $\mathrm{Cu}$, atomic number, temperatures, time annealing temperature on the structure, crystallization temperature and crystallization process of $\mathrm{Ni}_{1-\mathrm{x}} \mathrm{Cu}_{\mathrm{x}}$ bulk; $\mathrm{x}=0: 1$, 0.3, 0.5, 0.7, International Journal of Modern Physics B, vol. 32, Article ID 1830009, 2018.

[42] T. Dung Nguyen, "Some factors affecting structure, transition phase and crystallized of CuNi nanoparticles," American Journal of Modern Physics, vol. 6, no. 4, pp. 66-75, 2017.

[43] T. T. Quoc and D. N. Trong, "Molecular dynamics factors affecting on the structure, phase transition of Al bulk," Physica B: Condensed Matter, vol. 570, pp. 116-121, 2019.

[44] L. Néel, "Propriétés magnétiques des ferrites ferrimagnétisme et antiferromagnétisme," Annals of Physics, vol. 3, no. 2, pp. 137-198, 1948.

[45] J. Strecka, "Exact results of a mixed spin-1/2 and spin-s Ising model on a bathroom tile (4-8) lattice: effect of uniaxial singleion anisotropy," Physica 280 A: Statistical Mechanics and its Applications, vol. 360, no. 2, pp. 379-390, 2006.

[46] L. Verlet, "Computer "experiments" on classical fluids. I. thermodynamical properties of Lennard-Jones molecules," Physical Review, vol. 159, no. 1, pp. 98-103, 1967.

[47] A. P. Sutton and J. Chen, "Long-range finnis-sinclair potentials," Philosophical Magazine Letters, vol. 61, no. 3, pp. 139-146, 1990.

[48] M. S. Daw and M. I. Baskes, "Semiempirical, quantum mechanical calculation of hydrogen embrittlement in metals," Physical Review Letters, vol. 50, no. 17, pp. 1285-1288, 1983.

[49] M. S. Daw and M. I. Baskes, "Embedded-atom method: derivation and application to impurities, surfaces, and other defects in metals," Physical Review B, vol. 29, no. 12, pp. 6443-6453, 1984.

[50] S. Ozgen and E. Duruk, "Molecular dynamics simulation of solidification kinetics of aluminium using Sutton-Chen version of EAM," Materials Letters, vol. 58, no. 6, pp. 1071-1075, 2004.

[51] Y. Kimura, Y. Qi, T. Ça gin, and W. A. Goddard III, “The quantum sutton-chen many-body potential for properties of Fcc metals," Pasadena: Caltech ASCI, vol. 3, pp. 1-29, 1998, Technical Report.

[52] S. Nosé, "A unified formulation of the constant temperature molecular dynamics methods," The Journal of Chemical Physics, vol. 81, no. 1, pp. 511-519, 1984.

[53] W. G. Hoover, "Canonical dynamics: equilibrium phase-space distributions," Physical Review A, vol. 31, no. 3, pp. 1695-1697, 1985. 
[54] D. J. Lacks, "First-order amorphous-amorphous transformation in silica," Physical Review Letters, vol. 84, pp. 46294632, 2000.

[55] G. Guitierrez and B. Johansson, "Molecular dynamics study of structural properties of amorphous $\mathrm{Al}_{2} \mathrm{O}_{3}$," Physical Review $B$, vol. 65, pp. 104202-104210, 2002.

[56] V. Van Hoang and S. Kun Oh, "Annealing effects on structure in amorphous Al2O3 models," Physica B: Condensed Matter, vol. 364, no. 1-4, pp. 225-232, 2005.

[57] V. V. Hoang, "Glass of monatomic Lennard-Jones system at nanoscale," Physica B: Condensed Matter, vol. 405, no. 7, pp. 1908-1914, 2010.

[58] V. Van Hoang, T. Odagaki, and M. Engel, "Cooling rate effects on structure and thermodynamics of amorphous nanoparticles," Applied Surface Science, vol. 254, no. 23, pp. 7531-7534, 2008.

[59] R. E. Dinnebier and S. J. L. Billinge, Powder Diffraction: Theory and Practicepp. 470-473, Royal Society of Chemistry, Cambridge, UK, 1st edition, 2008.

[60] D. Chandler, Introduction to Modern Statistical Mechanics, Oxford University Press, UK, 1987, https://www.google.com/ search?client=firefox-b-ab\&q=Oxford\&stick=H4sIAAAAAA AAAOPgE-LQz9U3SK6qylECs0xzTPO0ZIqLrfTLU5PSEpN Liq0yUhNTCksTi0ric_KTE0sWsbL5V6TlF6UAAL0mI7I9A AAA\&sa $=$ X\&ved $=2$ ahUKEwjz4Kf4-7zyAhWT4zgGHcMjD L8QmxMwFnoECAwQCQ.

[61] J. L. Yarnell, M. J. Katz, R. G. Wenzel, and S. H. Koenig, "Structure factor and radial distribution function for liquid argon at $85^{\circ} \mathrm{K}$," Physical Review A, vol. 7, no. 6, pp. 2130-2144, 1973.

[62] U. Gasser, E. R. Weeks, A. Schofield, P. N. Pusey, and D. A. Weitz, "Real-space imaging of nucleation and growth in colloidal crystallization," Science, vol. 292, no. 5515, pp. 258-262, 2001.

[63] M. I. Ojovan and D. V. Louzguine-Luzgin, "Revealing structural changes at glass transition via radial distribution functions," The Journal of Physical Chemistry B, vol. 124, no. 15, pp. 3186-3194, 2020.

[64] E. R. Weeks, J. C. Crocker, A. C. Levitt, A. Schofield, and D. A. Weitz, "Three-dimensional direct imaging of structural relaxation near the colloidal glass transition," Science, vol. 287, no. 5453, pp. 627-631, 2000.

[65] H. D. Thi Minh, G. Coman, H. N. Quang, and D. N. Trong, "Influence of heating rate, temperature, pressure on the structure, and phase transition of amorphous Ni material: a molecular dynamics study," Heliyon, vol. 6, no. 11, Article ID e05548, 2020.

[66] J. Li, "AtomEye: an efficient atomistic configuration viewer," Modelling and Simulation in Materials Science and Engineering, vol. 11, no. 2, pp. 173-177, 2003.

[67] G. J. Ackland and A. P. Jones, "Applications of local crystal structure measures in experiment and simulation," Physical Review B: Condensed Matter and Materials Physics, vol. 73, Article ID 054104, 2006.

[68] P. J. Steinhardt, D. R. Nelson, and M. Ronchetti, "Bondorientational order in liquids and glasses," Physical Review B, vol. 28, no. 2, pp. 784-805, 1983.

[69] Ş. Ţălu, M. Bramowicz, S. Kulesza, V. Dalouji, S. Solaymani, and S. Valedbagi, "Fractal features of carbon-nickel composite thin flms," Microscopy Research and Technique, vol. 79, pp. 1208-1213, 2016.

[70] Ş. Ţălu, M. Bramowicz, S. Kulesza et al., "Infuence of annealing process on surface micromorphology of carbon-nickel composite thin flms," Optical and Quantum Electronics, vol. 49, Article ID 204, 2017.

[71] T. Shen, W. Meng, Y. Wu, and X. Lu, "Size dependence and phase transition during melting of fcc-Fe nanoparticles: a molecular dynamics simulation," Applied Surface Science, vol. 277, pp. 7-14, 2013.

[72] F. Ding, A. Rosén, and B. Kim, "Size dependence of the coalescence and melting of iron clusters: a molecular-dynamics study," Physical Review B, vol. 70, Article ID 075416, 2004. 